\title{
Doğum Şeklinin Gençlerin Sağlık Durumu ile İlişsisi*
}

\author{
Gizem GÜNEŞ ÖZTÜRK 國, Zekiye KARAÇAM ${ }^{1}{ }^{1}$, Kardelen TAZEGÜL ${ }^{1}$, \\ Leyla Nur KESER 國
}

\section{ÖZ}

Amaç: Araştırmanın amacı, doğum şeklinin gençlerin sağlık durumuna etkisini incelemektir.

Gereç ve Yöntemler: Araştırma analitik-kesitsel olarak Şubat-Mart 2018 tarihleri arasında, Adnan Menderes Üniversitesi Sağlık Bilimleri ve Hemşirelik Fakültelerinde yapılmıştır. Araştırmanın örneklemine gelişigüzel örnekleme yöntemi ile 482 öğrenci dâhil edilmiştir. Verilerinin toplanmasında, soru formu ve SF-36 Kısa Form Yaşam Kalitesi Ölçeği kullanılmıştır. Araştırmada gençlerin genel sağlık durumunu belirlemede, SF-36 yaşam kalitesi ölçeği genel popülasyonda fiziksel, mental ve genel sağlık durumu hakkında veri elde etmede kullanıldığı için tercih edilmiştir. Verilerin analizinde tanımlayıcı istatistikler (ortalama, sayı, yüzde) ve t-testi kullanılmıștır.

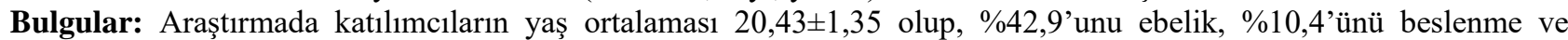
diyetetik ve \%46,7'sini hemşirelik bölümü öğrencileri oluşturmuştur. Öğrencilerin \%13,7'si birinci, \%40,2'si ikinci, \%33,2'si üçüncü ve \%12,9'u dördüncü sinıflarda öğrenim görmektedir. Öğrencilerin \%3,9'unun gelir getiren bir işte çalıştığı, \%19,1'inin sigara kullandığı ve \%3,7'sinin alkol kullandığı saptanmıştır. Çalışmadaki öğrencilerin \% \%,7'si fiziksel bir rahatsızlığı olduğunu ve \%8,9'u sürekli kullandığı ilacının olduğunu bildirmişlerdir. Araştırmadaki öğrencilerin \%20'sinin doğum şeklinin sezaryen olduğu saptanmıştır. Öğrencilerin SF-36 toplam ölçek puan ortalaması $66,84 \pm 12,75$ olarak belirlenmiş olup, fonksiyonel durum, esenlik ve genel sağlık ölçeği alt ölçek puan ortalamaları sırasıyla $81,46 \pm 13,78 ; 59,34 \pm 15,18 ; 61,58 \pm 17,38$ olarak saptanmıştır. Doğum şekline göre toplam SF-36 yaşam kalitesi ölçeği ve alt ölçek puanları arasında istatistiksel olarak anlamlı bir fark bulunmamıştır.

Sonuç: Bu çalışmada doğum şeklinin gençlerin sağlık durumunu etkilemediği sonucu elde edilmiştir. Bu çalışmanın sonuçlarını destekleyebilecek farklı örneklem grupları ile benzer çalışmaların yapılması önerilebilir.

Anahtar Kelimeler: Sezaryen doğum; normal doğum; ebelik; sağlık durumu.

\section{The Relation of the Mode of Delivery with the Health Status of Young People}

\begin{abstract}
Aim: The aim of the study is to examine the effects of mode of delivery on the health status of young people.

Material and Methods: The study was made analytical-cross-section between February and March 2018 at Adnan Menderes University, Faculties of Health Sciences and Nursing. 482 students were included in the study sample by convenience sampling method. The questionnaire and the SF-36 Health Survey scale were used to collect the data. The SF-36 was chosen because it was used to obtain data on physical, mental and general health status in the general population. Descriptive statistics (mean, number, percentage) and t-test were used in the analysis of the data.

Results: The average age of the participants was $20.43 \pm 1.35,42.9 \%$ were midwifery, $10.4 \%$ were nutrition and dietetics and $46.7 \%$ were nursing students. Of the students, $13.7 \%$ were in the first, $40.2 \%$ in the second, $33.2 \%$ in the third and $12.9 \%$ in the fourth grade. In the study, 3.9\% of the students worked in an income generating business, $19.1 \%$ of them smoked and $3.7 \%$ of them used alcohol. They reported that $7.7 \%$ of the students in the study had a physical illness and $8.9 \%$ of them used a drug regularly. It was determined that $20 \%$ of the students in the study had a caesarean delivery pattern. The average total score of SF-36 students was $66.84 \pm 12.75$, and the functional subscale, wellbeing
\end{abstract}

1 Aydın Adnan Menderes Üniversitesi, Sağlık Bilimleri Fakültesi, Ebelik Bölümü, Aydın, Türkiye

*Bu çalışma 07-09 Kasım 2018 tarihleri arasında İzmir'de düzenlenen 1. Uluslararası Ebelik Eğitim Araştırma Geliştirme (EBEARGE) Kongresinde sözel bildiri olarak sunulmuş ve tam metin olarak yayınlanmıştır. 
subscale and public health subscale average scores were respectively $81.46 \pm 13.78,59.34 \pm 15.18$ and $61.58 \pm 17.38$. According to mode of delivery, there was no statistically significant difference for the total SF-36 quality of life scale score and subscale scores.

Conclusion: The study revealed that caesarean births did not affect the health status of young people. It may be advisable to perform similar studies with different sample groups to support the results of this study.

Keywords: Caesarean delivery; vaginal delivery; midwifery; health status.

\section{GíRIŞ}

Sezaryen doğum, gerekli olduğu zaman uygulandığında, maternal ve perinatal mortalite ve morbiditeyi önleyebilen yaşamı koruyucu bir cerrahi işlemdir. Dünya Sağlık Örgütü (DSÖ), yaşamı koruyabilecek sezaryen oranının \%10-15 olmasını önermekte ve \%10'dan daha fazla olan sezaryenin, mortalite oranlarını azalttı̆̆ına dair herhangi bir kanıt bulunmadığını bildirmektedir. Diğer yandan, son yıllarda, sezaryen ile doğum oranları, bazı ülkelerde olduğu gibi (1) Türkiye'de de kontrolsüz bir biçimde giderek artmış ve her iki bebekten biri sezaryen ile doğar konuma gelmiştir (2). Bu yüksek sezaryen oranlarının, yaşamı korumanın ötesinde, anne ve bebeğin fiziksel, sosyal ve psikolojik iyilik durumunun yanında ekonomik olarak olumsuz etkileri bulunmaktadır $(1,3,4)$. $\mathrm{Bu}$ nedenle sezaryen doğum sonuçlarının daha fazla anlaşılması gerekmektedir. $\mathrm{Bu}$ durum ülkemiz için de önemle üzerinde durulması ve çalışılması gereken bir konudur.

Sağlık Bakanlığı verilerine göre 2015 yılında doğan çocukların \%53'ü sezaryen ile dünyaya gelmiştir (2). Bu oran, DSÖ’nün önerisinden (\%10-15) yaklaşık 4-5 kat daha fazladır. $\mathrm{Bu}$ nedenle sezaryenin, uzamış doğum eylemi, fetal distres ya da pozisyon bozukluğu gibi vajinal doğumun anne-bebek için risk oluşturduğu durumlarda uygulanması önerilmektedir. Ayrıca sezaryen, özellikle kapsamlı obstetrik bakıma ulaşılamadığında ve güvenli cerrahi koşullar oluşturulamadığında olası ciddi komplikasyonlara, morbidite ve mortaliteye neden olabilmektedir (1).

Yapılan çalışmalarda sezaryen ile doğan çocukların yaşamları boyunca alerji, astım, şeker ve bağırsak hastalıkları gibi bazı hastalıklardan daha fazla etkilendikleri bildirilmektedir. Yine sezaryen ile doğan çocuklarda otizm, hiperaktivite bozuklukları, öğrenme güçlükleri gibi durumların daha fazla görüldüğü rapor edilmektedir (5-7).

Ebelerin sezaryen doğumların azaltılması ve bu konuya bağlı anne-bebek sağlığının geliştirilmesinde önemli sorumlukları bulunmaktadır (8-10). Ebeler gebelik ve doğum süresinde gebe ve ailesine özellikle isteyerek sezaryen doğumların azaltılması konusunda eğitim ve danışmanlık yapabilirler. Ayrıca ebeler, etkili intrapartum bakım ile sezaryen doğumların azaltılmasına katkı sağlayabilirler (11-13).

Ülkemizde, yüksek sezaryen doğum oranları, önemli bir sağlık sorunudur. Sezaryen doğumun anne-bebek sağlığına olan kısa süreli etkileri ile ilgili önemli kanıtlar bulunmaktadır $(3,5,6)$. Ancak sezaryen doğumların uzun süreli etkileri ile ilgili daha fazla çalışmaya gereksinim bulunmaktadır.

$\mathrm{Bu}$ araştırmanın amacı, doğum şeklinin gençlerin sağlık durumu ile ilişkisini incelemektir. $\mathrm{Bu}$ amaç doğrultusunda; (1) Gençlerin sağlık durumu nasıldır? (2) Doğum şeklinin gençlerin sağlık durumu ile ilişkisi var mıdır? araştırma sorularına yanıt aranmıştır.

\section{GEREÇ VE YÖNTEMLER \\ Araştırma Türü}

Araştırma karşılaştırmalı analitik-kesitsel olarak ŞubatMayıs 2018 tarihleri arasında, Adnan Menderes Üniversitesi Sağlık Bilimleri ve Hemşirelik Fakültelerinde yapılmıştır.

\section{Araştırma Evreni ve Örneklemi}

Araştırmanın evrenini, 2017-2018 eğitim-öğretim yılında Adnan Menderes Üniversitesi Sağlık Bilimleri ve Hemşirelik Fakültelerinde öğrenim gören öğrenciler (toplam 2000 öğrenci) oluşturmuştur. Araştırmanın örneklemine gelişigüzel örnekleme yöntemi ile 482 kişi dâhil edilmiştir. Araştırmaya alınması gereken en az birey sayısı daha önce hemşireler ile yapılan bir çalışmaya (14) dayalı olarak hesaplanmıştır. Bu araştırmanın verilerine dayalı olarak yapılan analizde, $\mathrm{G}^{*}$ Power 3.1.9.2 ile power: $0,95, \alpha=0,05$, örneklem hacmi; 118 alınarak yapilan hesaplamada effect size: 0,47 olarak bulunmuştur. $\mathrm{Bu}$ araştırmanın örneklemine alınması gereken en az birey sayıs1, temel istatistik t-test ile yapılacağından, $G^{*}$ Power 3.1.9.2 ile effect size: 0,30, $\alpha=0,05$ ve power: 0,95 alınarak hesaplanmış ve 484 olarak bulunmuştur. Örnek araştırmadan elde edilen etki büyüklüğü büyük olduğundan daha fazla örneklem hacmine ulaşmak için orta etki (effect size: 0,30) büyüklüğünün kullanılması tercih edilmiştir.

Araştırma, 2017-2018 eğitim-öğretim yılında, Adnan Menderes Üniversitesi Sağlık Bilimleri ve Hemşirelik Fakültelerinde öğrenim gören öğrenciler ile gerçekleştirilmiştir. Çalışmada, verilerin toplandığ günde, araştırma için belirlenen derse katılmak üzere sınıfta bulunan öğrenciler çalışmaya davet edilmiş ve kabul eden 482 kişi dâhil edilmiştir. Araştırmaya dâhil edilmeme kriterlerini ise soru formunun önemli bölümlerini (SF- 36 Kısa Form Yaşam Kalitesi Ölçeği ve sağlik durumunu sorgulayan sorular) tamamlamama oluşturmuştur. Araştırma verileri, sınıf ortamında kendini bildirim yöntemi ile toplanmıştır. Verilerin toplanmasında öncelikle gençlere araştırma hakkında bilgi verilmiş, araştırmaya katılmaya davet edilmiş ve gönüllü olur formundaki bilgiler okunarak onamları alınmıştır. Araştırmaya katılmayı kabul eden gençlere veri toplama formları dağıtılmış ve gözlem altında soru formu ve SF-36 Kısa Form Yaşam Kalitesi Ölçeğini doldurmaları sağlanmıştır. Görüşmeler yaklaşık 20 dakika sürmüştür. Çalışmaya davet edilen öğrencilerin tamamı veri toplama formlarını doldurmuştur.

\section{Veri Toplama Araçları}

Araştırma verilerinin toplanmasında, soru formu ve SF36 Kısa Form Yaşam Kalitesi Ölçeği kullanılmıştır. SF36 Yaşam Kalitesi Ölçeği genel popülasyonun incelenmesinde kullanılan bir ölçek olduğu için, bu çalışmada kullanılması uygun görülmüştür. 
Soru formu, araştırmacılar tarafından konu ile ilgili literatüre dayalı olarak hazırlanmıştır (15-17). Formda gençlerin tanıtıcı özelliklerini (yaş, cinsiyet, sınıf, şu anda yaşadığ 1 yer, aile özellikleri, ekonomik durum, geçirdiği hastalık, kullandığı ilaçlar, alışkanlıkları, doğum şekli) sorgulayan 15 ve fiziksel sağlık durumunu belirlemede yararlanılan üç soru bulunmaktadır. Bu formun kapsam geçerliğini sağlamak için bilimsel araştırmalar konusunda deneyimli uzmanların görüşleri alınmış ve yapılan öneriler doğrultusunda yeniden düzenleme yapılmıştır. Daha sonra bu formun anlaşılabilirliği ve uygulanabilirliğini geliştirmek için araştırma kapsamına alınmayan 10 genç ile ön uygulama yapılmış ve formda değişiklik yapılmadığından ön uygulamada elde edilen veriler analize alınmıştır.

SF- 36 Klsa Form Yaşam Kalitesi Ölçeği (The MOS 36 Item Short Form Health Survey): Bu ölçek Ware (18) tarafından klinik uygulama ve araştırmalarda sağlık politikalarının değerlendirilmesinde ve genel popülasyonun incelenmesinde kullanılmak üzere geliştirilmiştir. Ölçek 36 ifadeden oluşmakta ve üç ana başlıkta dokuz sağlık kavramını değerlendirmektedir. Ölçekte yer alan ana başliklar; fonksiyonel durum, esenlik ve genel sağlık anlayışıdır. Fonksiyonel durum; sağlık problemlerine bağlı olarak fiziksel aktivitelerin kısıtlanması, emosyonel ve sosyal problemlere bağlı sosyal aktivitelerin kısıtlanması, fiziksel sağlık problemlerine bağlı olarak günlük yaşam aktivitelerinin yapılmasının engellenmesi ve emosyonel sağlık problemlerine bağlı olarak günlük yaşam aktivitelerinin yapılmasının engellenmesi kavramlarını içermektedir. Esenlik; mental sağlık, beden ağriları ve canlılı̆̆ içermektedir. Genel sağlık anlayışı ise; bir bütün olarak sağlığın değerlendirilmesi ve geçen yıl süresince sağlıktaki değişimleri kapsamaktadır. Ölçeğin fonksiyonel durum, esenlik ve genel sağlık anlayışı olmak üzere üç alt başlıkta toplanan alt ölçekleri global yaşam doyumu/kalitesini oluşturmaktadır. Bireylerin alabileceği toplam ölçek puanı, üç temel alt ölçeğin her biri ve global yaşam doyumu ölçeği için 0-100 arasında değişmektedir. Ölçek, Pınar (19) tarafından Türkçe'ye uyarlanmış ve Cronbach alfa değerinin 0,91 olduğu bildirilmiştir. $\mathrm{Bu}$ çalışmanın verilerine dayalı olarak yapılan hesaplamada ölçeğin Cronbach alfa değeri 0,89 olarak bulunmuştur.

\section{Araştırmanın Etik Boyutu}

Araştırma protokolü ile ilgili Adnan Menderes Üniversitesi Sağlık Bilimleri Fakültesi Girişimsel Olmayan Klinik Araştırmalar Etik Kurulu'ndan etik kurul oluru alınmıştır (Sayı: 92340882-050.0404; Tarih: 27.12.2017). Araştırma verilerinin toplanabilmesi için Adnan Menderes Üniversitesi Sağlık Bilimleri ve Hemşirelik Fakülteleri Dekanlıklarından (Sayı: 92340882-044; Tarih: 09/02/2018) izin alınmıştır. Araştırmaya dâhil edilen gençlere araştırma ile ilgili bilgi verilmiş, çalışmaya katılmaya davet edilmiş, sözlü ve yazılı onamları alınmıştır. Çalışma Helsinki Deklarasyonu Prensipleri'ne uygun olarak yapılmıştır.

\section{İstatistiksel Analiz}

Araştırmadan elde edilen veriler Adnan Menderes Üniversitesi'nde kullanılan istatistik paket programı Statistical Package for the Social Sciences Version 18,0
(SPSS Inc., IL, USA) ile analiz edilmiştir. Araştırmanın bağımlı değişkenlerini SF-36 toplam ve esenlik, genel ve fonksiyonel durum alt ölçek puanları, bağımsız değişkenini ise öğrencilerin doğum şekli oluşturmuştur. Araştırmanın SF-36 toplam, esenlik, genel ve fonksiyonel durum bağımlı değişkenlerinin normal dağılıma uygun olduğu sonucuna varılmıştır (20). Verilerin analizinde tanımlayıcı istatistikler (ortalama, sayı, yüzde, vb.), Cronbach alfa katsayısı ve t-testi kullanılmıştır. Değerlendirmede, $p \leq 0,05$ olan değerler istatistiksel olarak anlamlı kabul edilmiştir.

\section{BULGULAR}

Araştırmaya katılan öğrencilerin yaş ortalaması

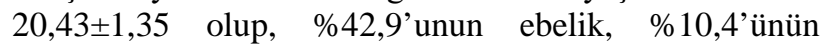
beslenme ve diyetetik ve \%46,7'sinin hemşirelik bölümünde öğrenim gördükleri saptanmıştır. Öğrencilerin \%40,2'sinin ikinci ve \%33,2'sinin üçüncü sınıfta okuduğu bulunmuştur. Çalışmadaki öğrencilerin \%42,1'inin il merkezinde ikamet ettiği, \%3,9'unun $(n=16)$ gelir getiren bir işte çalıştığı ve \%11,1'inin sağlık güvencesinin olmadığı saptanmıştır. Öğrencilere gelir durumları sorulduğunda, \%20,5'i gelirlerinin giderlerinden düşük olduğunu bildirmişlerdir. Öğrencilerin \%17,1'inin yaşamında önemli bir stres yaratan durum ile karşılaştığı, \%18,8'inin sigara ve \%3,7'sinin alkol kullandığı saptanmıştır. Araştırmada öğrencilerin \%20'sinin (n=94) sezaryen ile doğdukları belirlenmiştir (Tablo 1).

Çalışmadaki öğrencilerin \% $\%$,3'ünün fiziksel bir rahatsızlığının bulunduğu ve en sık görülen fiziksel rahatsızlıkların kalp hastalıkları, solunum hastalıkları ve kas-iskelet hastalıkları olduğu belirlenmiştir. Yine öğrencilerin \%8,9'unun sürekli ilaç kullandığı ve en çok kullanılan ilaç gruplarının hormonal ilaçlar, vitaminler ve antianemikler olduğu saptanmıştır. Öğrencilerin \%81,9'u kendilerini sağlıklı olarak tanımlamışlardır (Tablo 2).

Öğrencilerin annelerinin yaş ortalaması 46,30 $\pm 5,17$ olup, \%67,2'sinin ilkokul / ortaokul ve \%19,5'inin lise mezunu oldukları görülmüştür. Babalarının yaş ortalaması ise $50,40 \pm 5,45$ 'dir ve yine annelerde olduğu gibi çoğunun ilkokul / ortaokul $(\% 53,4)$ ve lise $(\% 29,8)$ mezunu oldukları belirlenmiştir.

Öğrencilerin SF-36 toplam ölçek ve alt ölçek puan ortalamaları Tablo 3'te verilmiştir. Öğrencilerin SF-36 toplam ölçek ve alt ölçek puan ortalamalarının doğum şekline göre dağılımı incelendiğinde istatistiksel olarak anlamlı bir fark bulunmamıştır (Tablo 4).

\section{TARTIŞMA}

$\mathrm{Bu}$ çalışma doğum şeklinin gençlerin genel sağlık durumuna etkisinin incelenmesi amacı ile yapılmıştır. Çalışmada öğrencilerin çoğunun normal doğum ile doğdukları ve doğum şeklinin gençlerin fonksiyonel durum, esenlik ve genel sağlık durumu üzerinde anlamlı bir etkisinin olmadığı sonuçları elde edilmiştir. $\mathrm{Bu}$ sonuçlar doğum şeklinin gençlerin sağlık durumunu etkilemediğini ortaya koyması bakımından önemlidir.

Araştırmada öğrencilerin önemli bir bölümü sezaryen (\%20) ile doğmuşlardır. Öğrencilerin doğum yılları 19962000 arasında değişmektedir. Bu sonuçlara benzer olarak 
Tablo 1. Öğrencilerin sosyo-demografik özellikleri ve doğum şekilleri $(\mathrm{n}=482)$

\begin{tabular}{|c|c|c|}
\hline \multicolumn{3}{|l|}{ Özellikler } \\
\hline \multirow[t]{2}{*}{$\operatorname{Yaş}^{*}\left(n=480^{\#}\right)$} & \multicolumn{2}{|c|}{$20,43 \pm 1,35(18-29)$} \\
\hline & $\mathbf{n}$ & $\%$ \\
\hline \multicolumn{3}{|l|}{ Bölüm } \\
\hline Ebelik & 207 & 42,9 \\
\hline Beslenme ve Diyetetik & 50 & 10,4 \\
\hline Hemşirelik & 225 & 46,7 \\
\hline \multicolumn{3}{|l|}{ Sinıf } \\
\hline 1. sinif & 66 & 13,7 \\
\hline 2. sinif & 194 & 40,2 \\
\hline 3.sinif & 160 & 33,2 \\
\hline 4. sinif & 62 & 12,9 \\
\hline \multicolumn{3}{|l|}{ Çalışma durumu } \\
\hline Hayır & 463 & 96,1 \\
\hline Evet & 19 & 3,9 \\
\hline \multicolumn{3}{|l|}{ Mesleği } \\
\hline Öğrenci & 466 & 96,7 \\
\hline Çalışan (memur, işçi, s. meslek) & 16 & 3,3 \\
\hline Sağlık güvencesi olmayan $\left(n=477^{\#}\right)$ & 53 & 11,1 \\
\hline \multicolumn{3}{|l|}{ İkamet yeri } \\
\hline İl merkezi & 203 & 42,1 \\
\hline İlçe merkezi & 178 & 36,9 \\
\hline Kasaba & 23 & 4,8 \\
\hline Köy & 78 & 16,2 \\
\hline \multicolumn{3}{|l|}{ Algılanan gelir durumu $\left(n=479^{\#}\right)$} \\
\hline Gelir giderden düşük & 98 & 20,5 \\
\hline Gelir gidere denk & 344 & 71,8 \\
\hline Gelir giderden fazla & 37 & 7,7 \\
\hline \multicolumn{3}{|l|}{ Aile tipi $\left(n=478^{\#}\right)$} \\
\hline Geniş aile & 49 & 10,3 \\
\hline Çekirdek aile & 429 & 89,7 \\
\hline \multicolumn{3}{|l|}{ Sigara kullanımı $\left(n=467^{\#}\right)$} \\
\hline Hiç sigara kullanmam & 298 & 63,8 \\
\hline Ara sıra kullanırım & 81 & 17,3 \\
\hline Sigara kullanırım & 88 & 18,8 \\
\hline
\end{tabular}

Günlük sigara kullanım sayısı*

(n=89)

\begin{tabular}{|c|c|c|}
\hline \multirow{2}{*}{\multicolumn{3}{|c|}{$\frac{(n=89)}{\text { Alkol kullanumi }\left(n=354^{\#}\right)}$}} \\
\hline & & \\
\hline Hayır, hiç kullanmam & 216 & 61 \\
\hline Ara sira kullanırım & 125 & 35,3 \\
\hline Evet, kullanıyorum & 13 & 3,7 \\
\hline $\begin{array}{l}\text { Haftalık alkol kullanım sıklığı* } \\
(n=15)\end{array}$ & \multicolumn{2}{|c|}{$2,66 \pm 1,67(1-7)$} \\
\hline \multicolumn{3}{|l|}{ Diğer alıșkanlıklar $\left(\mathrm{n}=7^{\#}\right)$} \\
\hline Uyuşturucu & 4 & 0,8 \\
\hline Bilgisayar oyunu & 2 & 0,4 \\
\hline Kahve & 1 & 0,2 \\
\hline $\begin{array}{l}\text { Yaşamında önemli bir durum ile } \\
\text { karşıllaşma }\left(n=82^{\#}\right)\end{array}$ & 82 & 17,1 \\
\hline
\end{tabular}

\begin{tabular}{lcc}
\hline $\begin{array}{l}\text { Karşılaşılan önemli durumlar } \\
(\mathbf{n = 7 6})\end{array}$ & & \\
Hastalık & 18 & 23,7 \\
Ölüm & 32 & 42,1 \\
Evlilik & 6 & 7,9 \\
Boşanma & 9 & 11,8 \\
Taşınma & 4 & 5,3 \\
İş kaybı & 4 & 5,3 \\
Kaza & 2 & 2,6 \\
Ameliyat & 1 & 1,3 \\
\hline Doğum şekli $\left(\mathbf{n}=\mathbf{4 7 0}^{\#}\right)$ & & \\
Normal doğum & 376 & 80 \\
Sezaryen & 94 & 20 \\
\hline
\end{tabular}

*Ortalama \pm Standart Sapma (Minimum-Maksimum), s:serbest, ${ }^{*}$ Kayıp verilerden dolayı değişkenlerdeki n değerlerinde farklılık oluşmuştur.
Tablo 2. Öğrencilerin sağlık ile ilgili özellikleri

\begin{tabular}{|c|c|c|}
\hline Özellikler & $\mathbf{n}$ & $\%$ \\
\hline \multicolumn{3}{|l|}{$\begin{array}{l}\text { Bildirilen sağlık durumu } \\
\left(\mathrm{n}=454^{\#}\right)\end{array}$} \\
\hline Sağlıklı & 372 & 81,9 \\
\hline Orta & 54 & 11,9 \\
\hline Sağlıksız & 28 & 6,2 \\
\hline Fiziksel hastalığı sahip olma & 35 & 7,3 \\
\hline \multicolumn{3}{|l|}{ Fiziksel hastalık durumu* } \\
\hline Kalp hastalıkları & 7 & 19,6 \\
\hline Solunum hastalıkları & 7 & 19,6 \\
\hline Kas-iskelet hastalıkları & 7 & 19,6 \\
\hline Gastroenterolojik hastalıklar & 5 & 14,2 \\
\hline Endokrin sistemi hastalıkları & 4 & 11,4 \\
\hline Üreme sistemi hastalıkları & 4 & 11,4 \\
\hline Otoimmün hastalıklar & 2 & 5,7 \\
\hline Göz hastalıkları & 2 & 5,7 \\
\hline Hematolojik sistem hastalıkları & 2 & 5,7 \\
\hline Üriner sistem hastalıkları & 2 & 5,7 \\
\hline Nörolojik hastalıklar & 1 & 2,8 \\
\hline Cilt Hastalıkları & 1 & 2,8 \\
\hline Sürekli ilaç kullanımı & 43 & 8,9 \\
\hline \multicolumn{3}{|l|}{ Sürekli kullanılan ilaç* } \\
\hline Hormonal ilaçlar & 10 & 23,2 \\
\hline Vitaminler & 8 & 18,6 \\
\hline Antianemikler & 5 & 11,6 \\
\hline Antihistaminikler & 3 & 6,8 \\
\hline Antiastmatikler & 3 & 6,8 \\
\hline Antibiyotikler & 3 & 6,8 \\
\hline Antidiyabetikler & 3 & 6,8 \\
\hline Bronkodilatörler & 3 & 6,8 \\
\hline Antidepresanlar & 2 & 4,7 \\
\hline Antiglokomlar & 1 & 2,3 \\
\hline Proton pompa inhibitörleri & 1 & 2,3 \\
\hline Migren ilaçları & 1 & 2,3 \\
\hline
\end{tabular}

Sağlık Bakanlığı 2016 Sağlık İstatistikleri Yıllığına (7) göre Türkiye'de sezaryen oranı 2002 yılında \%21 olarak bildirilmiştir. Yine aynı raporda 2015 yılında sezaryen ile doğum oranının \%53'e yükseldiği görülmektedir. Yılmaz ve ark. (21) tarafindan yapılan çalışmada 2002 yılında $\% 37,7$ olan sezaryen oranının 2007 yılında \%51'e yükseldiği rapor edilmiştir. Coşkun ve ark. (22) yaptıkları çalıșmada 2004 yılında \%34,4 olan sezaryen oranının 2006 yılında \%40,2'ye yükseldiğini belirlemişlerdir. Bu sonuçlara dayalı olarak çalışmadaki öğrencilerin doğum şekillerinin ülkemiz geneline benzer olduğu söylenebilir. Daha sonraki yıllarda artan sezaryen oranları göz önüne alındığında sezaryenin sağlık üzerindeki uzun vadeli etkileri hakkında daha fazla çalışmaya ihtiyaç duyulmaktadır.

Öğrencilerin SF-36 fonksiyonel durum alt ölçek puanının, esenlik ve genel sağlık alt ölçek puan ortalamalarından daha yüksek olduğu belirlenmiştir. Genç ve ark. (23) tarafından kadın ve erkek genç erişkinler ile yapılan benzer bir çalışmada gençlerin fiziksel sağlık puanlarının çalışmada bildirilenden daha düşük, mental sağlık puanlarının ise daha yüksek olduğu saptanmıştır. Yine Vural ve ark. (24) tarafindan yapılan araştırmada masa başı işlerde çalıșan bireylerin fonksiyonel durum ve esenlik alt ölçek puanlarının araştırma sonuçlarına benzer olduğu, genel sağlık alt 
Tablo 3. SF 36 Yaşam Kalitesi Ölçeği toplam ve alt boyut puanlarına ait tanımlayıcı istatistikler

\begin{tabular}{|c|c|c|c|c|}
\hline & $\begin{array}{c}\text { Madde } \\
\text { sayısı }\end{array}$ & $\begin{array}{c}\text { Alınabilecek } \\
\text { alt ve üst } \\
\text { puanlar } \\
\end{array}$ & $\begin{array}{c}\text { Çalışmadan alınan } \\
\text { minimum- } \\
\text { maksimum puanlar }\end{array}$ & Ort \pm SS \\
\hline $\begin{array}{l}\text { SF } 36 \text { Yaşam Kalitesi Ölçeği } \\
\text { toplam puan }\left(n=432^{\#}\right)\end{array}$ & $36 *$ & & $22,02-93,58$ & $66,84 \pm 12,75$ \\
\hline \multicolumn{5}{|l|}{ Alt boyutlar } \\
\hline Fonksiyonel durum $\left(\mathrm{n}=447^{\#}\right)$ & 19 & $19-100$ & $22,86-100$ & $81,46 \pm 13,78$ \\
\hline Esenlik $\left(n=462^{\#}\right)$ & 11 & $11-100$ & $9,26-92,59$ & $59,34 \pm 15,18$ \\
\hline Genel sağlık $\left(\mathrm{n}=468^{\#}\right)$ & 5 & $5-100$ & $5-100$ & $61,58 \pm 17,38$ \\
\hline
\end{tabular}

Tablo 4. Doğum şekline göre SF 36 Yaşam Kalitesi Ölçeği toplam ve alt boyut puanlarına ait tanımlayıcı istatistikler ve karşılaştırma sonuçları

\begin{tabular}{|c|c|c|c|c|}
\hline \multirow[b]{2}{*}{ Ölçek ve alt boyutlar } & \multicolumn{2}{|c|}{ Doğum Şekli } & \multirow[b]{2}{*}{$\mathbf{t}$} & \multirow[b]{2}{*}{$\mathbf{p}$} \\
\hline & $\begin{array}{l}\text { Normal } \\
\text { Ort } \pm \text { SS } \\
\end{array}$ & $\begin{array}{c}\text { Sezaryen } \\
\text { Ort } \pm \text { SS }\end{array}$ & & \\
\hline Toplam ölçek puanı & $66,69 \pm 12,81$ & $66,69 \pm 12,81$ &,- 0552 & 0,581 \\
\hline Fonksiyonel durum & $81,26 \pm 14,17$ & $82,18 \pm 12,84$ & $-0,556$ & 0,579 \\
\hline Esenlik & $59,25 \pm 15,01$ & $59,68 \pm 16,27$ & $-0,240$ & 0,811 \\
\hline Genel Sağlık & $61,61 \pm 17,47$ & $61,61 \pm 17,16$ & $-0,250$ & 0,803 \\
\hline
\end{tabular}

ölçek puan ortalamasının ise daha yüksek olduğu belirlenmiştir. Bu sonuçlara göre yaşam kalitesi ölçeği alt ölçek puanlarının araştırmanın yapıldı̆̆ı örneklemin özelliklerine göre değişkenlik gösterebileceği söylenebilir. Burada esenlik alt ölçek puanlarını gösteren mental sağlık, vitalite ve ağrı parametrelerinin ve genel sağlık alt ölçek puanlarının fonksiyonel durum alt ölçek puanlarından daha düşük olması öğrencilerin sinirli veya depresif duygulanım içinde olduklarını, kendilerini yorgun ve bitkin hissettiklerini ve sağlıklarının kötü olduğuna ve giderek kötüleşeceklerine inandıklarını gösterebilir.

$\mathrm{Bu}$ çalışmada doğum şeklinin genel SF-36 Kısa Form Yaşam Kalitesi Ölçeği toplam puan ve alt ölçek puanlarını etkilemediği belirlenmiştir. DSÖ 2010 yılında yaptıkları uluslararası nitelikte bir çalışmada, tıbbi endikasyon olmaksızın yapılan sezaryen doğumun kısa vadede anne ve bebek üzerinde birçok olumsuz etkisinin olduğunu bildirmişlerdir. Fakat uzun vadeli olarak bu konuda bir çalışma yürütülmediği belirtilmiştir (25). Yine bu araştırma sonuçlarına benzer olarak Smithers ve ark. (6) tarafından yapılan bir çalışmada sezaryen ile doğumun çocukların 3-6 yaş arası yaşa göre boy, kilo ve beden kitle indeksi ölçümleri ile ilişkili olmadığ bildirilmiştir. $\mathrm{Bu}$ sonuçların aksine Darmasseelane ve arkadaşlarının (26) yaptıkları bir sistematik derlemede sezaryen doğum ile yetişkinlik döneminde aşırı kilo ve obezite arasında güçlü bir ilişkinin olduğu bildirilmiştir. Black ve arkadaşlarının (27) yaptıkları bir çalışmada vajinal olarak doğan çocuklarla karşılaştırıldığında sezaryen ile doğan çocukların 5 yaşa kadar hastaneye yatış gerektirecek astım, salbutamol kullanımı ve ölüm riskinin arttığı gösterilmiştir. Yine Keag ve ark. (28) yaptıkları bir meta-analizde sezaryen ile doğan çocuklarda 12 yaşına kadar astım riskinin, 5 yaşına kadar obezite riskinin yaklaşık 1,5 kat artmış olduğunu bildirmişlerdir. $\mathrm{Bu}$ sonuçlara dayalı olarak doğum şeklinin sağlık üzerindeki uzun vadeli etkilerinin çalışmaların sonuçlarına göre farklılık gösterdiği ve daha fazla bilgiye gereksinim olduğu söylenebilir.

\section{SONUC VE ÖNERILER}

$\mathrm{Bu}$ çalışmada doğum şeklinin gençlerin genel sağlık durumunu etkilemediği sonucu elde edilmiştir. Fakat daha önce yapılan çalışmaların bildirdiği yetişkin ve ileri yaş çocuklar üzerindeki etkileri (26-28) göz önüne alındığında, sezaryenin gençlerin genel sağlığı üzerinde etkisinin olmadığı söylenemez. Gelecekte yapılması planlanan araştırmalarda, Ülkemizde ve Dünya'da yükselen sezaryen oranları ile birlikte, sezaryenin sağlık üzerindeki uzun vadeli etkisinin varlığı ve bu etkinin nedensel veya karıştırıcı etkilerin bir sonucu olup olmadığı belirlenmelidir. Yine bu çalışmanın sonuçlarını destekleyebilecek farklı örneklem grupları ile daha kapsamlı çalışmaların yapılması da önerilebilir.

\section{TEŞEKKÜR}

Araştırma verilerinin toplanması sırasında yardımları için Aydın Adnan Menderes Üniversitesi Sağlık Bilimleri ve Hemşirelik Fakültelerinde görev yapan akademik personele ve yöneticilere ayrıca araştırmaya katılan tüm öğrencilere katkılarından dolayı teşekkür ederiz.

\section{KAYNAKLAR}

1. who.int [Internet]. Word Health Organization statement on caesarean section rates [Cited: 2018 Agust]. Available from:

http://apps.who.int/iris/bitstream/handle/10665/16144 2/WHO_RHR_15.02_eng.pdf;jsessionid=E1A6A456 664168A2A50D69D306255AD8?sequence=1.

2. Tuik.gov.tr [Internet]. İstatistiklerle Çocuk [Son güncelleme tarihi: 2016; Erişim tarihi: Ağustos 2018]. 
Erişim adresi: http://www.tuik.gov.tr/HbPrint.do?id=

3. Fobelets M, Beeckman K, Buyl R, Daly D, Sinclair M, Healy P, et al. Mode of birth and postnatal healthrelated quality of life after one previous cesarean in three European countries. Birth. 2018; 45(2): 137-47.

4. Kahraman ÖG, Ceylan Ş, Korkmaz E. 0-3 yaş arası çocukların gelişimsel değerlendirmelerinin bazı değişkenler açısından incelenmesi. Mersin Üniversitesi Sağlık Bilimleri Dergisi. 2016; 9(2): 609.

5. Petrou S, Kim SW, McParland P, Boyle EM. Mode of delivery and long-term health-related quality-of-life outcomes: A prospective population-based study. Birth. 2017; 44(2): 110-9.

6. Smithers LG, Mol BW, Jamieson L, Lynch JW. Cesarean birth is not associated with early childhood body mass index. Pediatric Obesity. 2017; 12(Supply 1): $120-4$.

7. Saglik.gov.tr [Internet]. Sağlık istatistikleri yıllı̆̆ 2016 [Son güncelleme tarihi: 2017; Erişim tarihi: Haziran 2018]. Erişim adresi: https://dosyasb.saglik.gov.tr/eklenti/13183,sy2016turk cepdf.pdf?0.

8. Arslan H, Karahan N, Çam C. The nature of midwifery and its effect on mode of childbirth. Maltepe University Nursing Science and Art Journal. 2008; 1(2): 55-8.

9. Internationalmidwives.org [Internet]. Essential competencies for basic midwifery practice [Cited: 2018 Agust]. Available from:

http://internationalmidwives.org/assets/uploads/docu ments/CoreDocuments/ICM\%20Essential\%20Compet encies\%20for\%20Basic\%20Midwifery\%20Practice\% 202010,\%20revised\%202013.pdf.

10. World Health Organization [Internet]. Midwifery [Cited: 2018 Agust]. Available from: http://www.who.int/topics/midwifery/en/.

11. Baas CI, Wiegers TA, de Cock TP, Erwich JJH, Spelten ER, De Boer MR, et al. Client-related factors associated with a "less than Good" experience of midwifery care during childbirth in the Netherlands. Birth. 2017; 44(1): 58-67.

12. Carlson NS, Corwin EJ, Lowe NK. Labor intervention and outcomes in women who are nulliparous and obese: comparison of nurse-midwife to obstetrician intrapartum care. Journal of Midwifery \& Women's Health. 2017; 62(1): 29-39.

13. Fontein JY. The comparison of birth outcomes and birth experiences of low-risk women in different sized midwifery practices in the Netherlands. Women and Birth. 2010; 23(3): 103-10.

14. Akbolat M, Turgut M, Över G. Hemşirelerin yaşam kalitesi algılarının motivasyonlarına etkisi: Bir kamu hastanesi örneği. Manas Sosyal Araştırmalar Dergisi. 2015; 4(2): 65-82.

15. Bingöl G, Gebeş R, Yavuz R. Amasya Sağlık Yüksekokulu öğrencilerinin genel sağlık durumlarının bazı değişkenlere göre incelenmesi. Göztepe Tıp Dergisi. 2012; 27(3): 106-11.

16. Şentürk M, Etiler N. Kocaeli Üniversitesi'nin üç meslek yüksekokulunda öğrencilerin sağlık
24645.

düzeylerinin algılanan sağlık ölçeği ve GSA-12 ile değerlendirilmesi, 2007. TAF Preventive Medicine Bulletin. 2009; 8(4): 307-14.

17. Uysal N, Yenal K. Hemşirelik öğrencilerinin genel sağlık durumlarının incelenmesi. SDÜ Sağlık Bilimleri Dergisi. 2014; 5(1): 15-20.

18. Ware JE. How to score the revised MOS Short-Form Health Scale (SF-36). Boston: MA: The Health Institute; 1988.

19. Pınar R. Diabetes Mellitus'lu hastaların yaşam kalitesi ve yaşam kalitesini etkileyen faktörlerin incelenmesi [Doktora tezi]. İstanbul: İstanbul Üniversitesi Sağlık Bilimleri Enstitüsü; 1995.

20. Tabachnick BG, Fidell LS. Using multivariate statistics. 6th ed. Boston: Pearson; 2013.

21. Yılmaz M, İsaoğlu Ü, Kadanalı S. Kliniğimizde 20022007 yılları arasında sezaryen olan hastaların incelenmesi. Marmara Medical Journal. 2009; 22(2): 104-10.

22. Coşkun A, Köstü B, Ercan Ö, Kıran H, Güven MA, Kıran G. Kahramanmaraş İl Merkezinde 2004 ve 2006 yıllarındaki doğumların karşılaştırılması. TJOD Dergisi. 2007; 4(3): 168-72.

23. Genç A, Şener Ü, Karabacak H, Üçok K. Kadın ve erkek genç erişkinler arasında fiziksel aktivite ve yaşam kalitesi farklılıklarının araştırılması. Kocatepe T1p Dergisi. 2011; 12(3): 145-50.

24. Vural Ö, Eler S, Güzel NA. Masa başı çalışanlarda fiziksel aktivite düzeyi ve yaşam kalitesi ilişkisi. Spormetre Beden Eğitimi ve Spor Bilimleri Dergisi. 2010; 8(2): 69-75.

25. Souza JP, Gulmezoglu AM, Lumbiganon P, Laopaiboon M, Carroli G, Fawole B, et al. Caesarean section without medical indications is associated with an increased risk of adverse short-term maternal outcomes: The 2004-2008 WHO global survey on maternal and perinatal health. BMC Medicine. 2010; 8(1): 71 .

26. Darmasseelane K, Hyde MJ, Santhakumaran S, Gale C, Modi N. Mode of delivery and offspring body mass index, overweight and obesity in adult life: A systematic review and meta-analysis. PloS One. 2014; 9(2): e87896.

27. Black M, Bhattacharya S, Philip S, Norman JE, McLernon DJ. Planned cesarean delivery at term and adverse outcomes in childhood health. JAMA. 2015; 314(21): 2271-9.

28. Keag OE, Norman JE, Stock SJ. Long-term risks and benefits associated with cesarean delivery for mother, baby, and subsequent pregnancies: Systematic review and meta-analysis. PLoS Medicine. 2018; 15(1): e1002494. 